\title{
A Short Review on Human Functional Neuropeptide Y Receptors
}

\author{
Gugan Kothandan ${ }^{1 \dagger}$ and Seung Joo $\mathrm{Cho}^{2,3 \dagger}$
}

\begin{abstract}
Neuropeptide Y (NPY), a 36-amino acid polypeptide, is a member of the pancreatic polypeptide family, which consists of NPY, peptide YY (PYY) and pancreatic polypeptide (PP). The neuropeptide Y (NPY) receptors called Y receptors belongs to G-protein coupled that are involved in a variety of physiological functions such as appetite regulation, circadian rhythm and anxiety. Five receptor subtypes have been cloned in mammals (Y1, Y2, Y4, Y5, and Y6) of which four are functional. In this short review, information about the functional NYP receptors was analyzed. Sequence analyses were done between these receptors to identify the relationships between them. Phylogram was generated between these receptors to identify the close homologue between these receptors. Our sequence analyses found that Y1 and Y4 receptors are close than the other receptors. Further structure based analysis could be useful to identify subtype selective antagonists and dual antagonists targeting Y1 and Y4 receptors.
\end{abstract}

Key words : Neuropeptide Y, Neuropeptide Y Receptor, Agonists, Antagonists

\section{Introduction}

To date, neuropeptide Y (NPY) has been the subject of over 10,000 research papers identifying its numerous roles in the body that include, among other things, the control of feeding behavior, cortical neural activity, heart activity and emotional regulation. Interestingly, NPY has also been implicated in several human diseases including obesity, alcoholism and depression, each of which might be considered to have behavioral or psychiatric components. Neuropeptide Y (NPY), a 36-amino acid polypeptide, is a member of the pancreatic polypeptide family, which consists of NPY, peptide YY (PYY) and pancreatic polypeptide (PP) ${ }^{[1,2]}$. NPY is highly concentrated in the hypothalamus ${ }^{[3,4]}$ and is a potent stimulator of food intake via NPY receptors, which belong to a family of $\mathrm{G}$ protein-coupled receptors $^{[5-9]}$

Neuropeptide $\mathrm{Y}$ and its receptors are expressed

${ }^{1}$ Department of Biohemistry, Centre for Bioinformatics, University of Madras, Guindy campus, Guindy, Chennai-600025, India

${ }^{2}$ Department of Bio-New Drug Development College of Medicine, Chosun University, Gwangju 501-759, Korea

${ }^{3}$ Department of Cellular $\cdot$ Molecular Medicine and Research Center for Resistant Cells, College of Medicine, Chosun University, Gwangju 501-759, Korea

†Corresponding author : guganmsc@gmail.com, chosj@chosun.ac.kr (Received: June 5, 2012, Revised : June 20, 2012, Accepted : June 24, 2012 throughout the body. In the central nervous system, they are located in many brain regions and in the spinal cord. In the periphery, NPY is notably located in the sympathetic nervous system, where it acts with nor epinephrine and adenosine triphosphate (ATP) to regulate cardiovascular and other functions. More recent findings suggest that NPY may even be involved in sweet and umami taste sensation ${ }^{[10]}$. Heterogeneity among NPY receptors was first proposed based on studies of sympathetic neuroeffector junctions, in which differential NPY signaling pharmacology was observed ${ }^{[11]}$.

To date, five distinct types of NPY receptors, Y1, Y2, Y4, Y5 and Y6, have been cloned ${ }^{[12]}$. Of which, Y1, Y2, $\mathrm{Y} 4$ and $\mathrm{Y} 5$ receptors have been grouped into the same family due to the fact that they all bind NPY. All NPY receptors are G protein-coupled receptors (Fig. 1) and activation by NPY primarily results in decreased cyclic adenosine monophosphate (cAMP) production in the cell. Activation of the G protein complex by NPY can also lead to depressed $\mathrm{Ca}^{2+}$ channel and enhanced $\mathrm{G}$ protein coupled inwardly rectifying potassium channel (GIRK) currents ${ }^{[13]}$.

In this review we analyzed the relationship between the Neuropeptide Y receptors which are activated by the closely related peptide hormones neuropeptide Y, peptide YY and pancreatic polypeptide. The complete information about each NPY receptors was analyzed, 


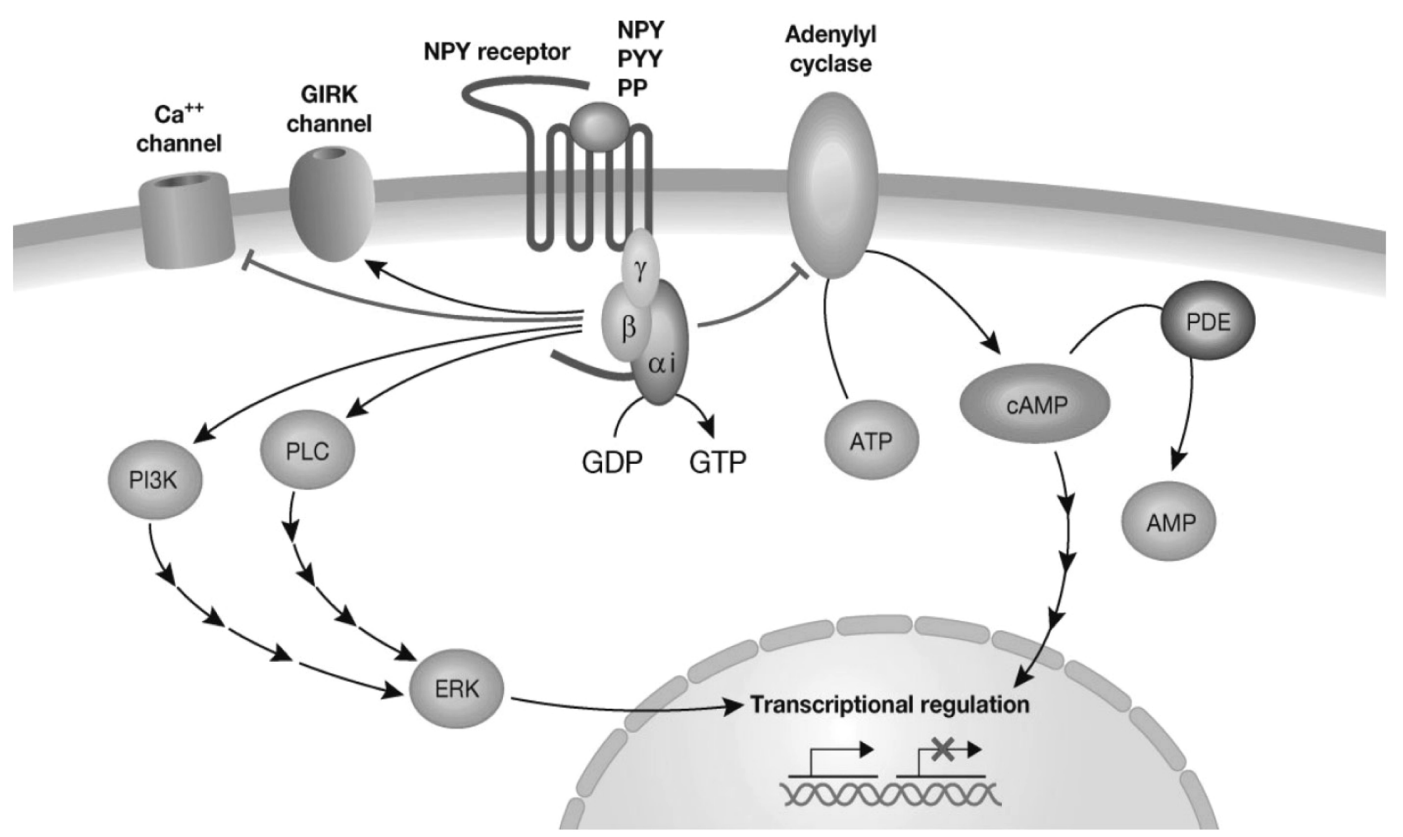

Fig. 1. Typical intracellular signaling cascades for NPY receptors.

which includes their sequential relationship between each others, sequential information about individual receptors, subtype agonists and subtype antagonists.

\section{NPY Receptor}

NPY receptors are a family of seven transmembrane G-protein coupled receptors, designated collectively as $\mathrm{Y}$ receptors that are expressed throughout the central and peripheral nervous systems where they mediate a variety of responses ranging from regulation of metabolism and food intake to regulation of neurotransmitter release in the vasculature and viscera ${ }^{[14]}$. The nomenclature reflects the large number of tyrosine $(\mathrm{Y}$ in the single letter code) present in their endogenous ligands, NPY, and the hormonal peptides, PYY and pancreatic polypeptide $^{[15]}$. NPY, peptide YY and pancreatic polypeptide elicit their physiological effects by interacting with at least six distinct $G$ protein-coupled receptors designated Y1, Y2, Y3, Y4, Y5 and Y $6^{[16]}$. With the exception of the NPY3 receptor, genes and/or cDNAs encoding each of these NPY receptors have been cloned. Among the cloned 5 subtypes Y1, Y2, Y4, Y5 and Y6, only four (Y1, Y2, Y4 and Y5) of them are functional in humans.
In contrast to other families of $\mathrm{G}$ protein-coupled receptors, the NPY receptors share only modest primary sequence homology (30-50\%). In fact, some NPY receptors are structurally more related to $\mathrm{G}$ protein-coupled receptors outside of the NPY receptor family. The structural differences among NPY receptors is beneficial to drug discovery efforts since compounds with high affinity for a particular NPY receptor are less likely to interact with other NPY receptors. In addition to having distinct amino acid sequences, each of the NPY receptors is characterized by a unique pharmacological profile and distinct tissue localization.

\subsection{The Neuropeptide Y1 Receptor}

The neuropeptide Y1 receptor was first characterized during the study of vascular muscle contraction effects of NPY ${ }^{[17]}$. The NPY1 receptor was pharmacologically defined by its high affinity for NPY and [Pro34] - peptide YY and its low affinity for N-terminally truncated NPY analogues. In the human, NPY1 receptor is expressed in kidney, heart, lung, colon, testis, adrenal gland, placenta, bone marrow and vascular smooth muscle. The human Y1 receptor was the first to be cloned encoded by NPY1R gene and is well characterized among the subtypes of NPY receptors pharmaco- 
logically ${ }^{[18,19]}$. This receptor subtype is stimulated by NPY and PYY. Using site-directed mutagenesis methods, the importance of certain acidic residues located in extracellular loops of the human Y1 receptor for NPY binding has been demonstrated ${ }^{[20]}$. The amino acid sequence of human NPY1 receptor is in UNIPROT database with the accession number P25929 and it composed of 384 residues. Neuropeptide Y and Peptide YY are reported agonists for this receptor. BVD-10, GR-231 and GR-118 are peptide based antagonists, whereas BIBO-3304, BIBP-3226, PD-160 and PD-170 are non peptide antagonists of NYP1 receptor.

\subsection{The Neuropeptide Y2 Receptor}

The neuropeptide Y2 receptor was also identified in early pharmacological studies as the NPY receptor responsible for regulation of noradrenalin release from sympathetic nerve terminals ${ }^{[17]}$. The NPY2 receptor is pharmacologically unique in that it has high affinity for N-terminally truncated NPY analogues and low affinity for [Pro34] peptide YY. Peptide fragments have been detected endogenously, but their physiological significance has not been determined ${ }^{[21]}$. The majority of NPY receptors in the central nervous system are probably of the $\mathrm{Y} 2$ subtype, especially with high densities seen in the hippocampal formation ${ }^{[22,23]}$. The human receptor was cloned independently by several research groups ${ }^{[24-26]}$. The amino acid sequence of human NPY2 receptor is deposited in UNIPROT database with the accession number P49146. This receptor is composed of 381 residues. Neuropeptide Y (endogenous agonist, non subtype selective), Neuropeptide Y fragment 13-36 (NPY selective agonist), 2-Thiouridine 5'-triphosphate, Peptide YY and Peptide YY 3-36 fragment are the reported agonist for this receptor. BIIE-0246, JNJ 5207787 and SF 11 are the reported antagonists for this receptor.

\subsection{The Neuropeptide Y4 Receptor}

The neuropeptide Y4 receptor was initially identified by molecular cloning. This receptor is pharmacologically characterized by its high affinity for pancreatic polypeptide and its low affinity for NPY. As the Y4 receptor binds PP with higher affinity than it binds NPY and PYY and is thus regarded as the PP receptor rather than a NPY receptor. Like PP, the Y4 receptor is mainly found in the gut ${ }^{[27]}$, but binding sites for PP and Y4 mRNA have also been found in several rat brain regions, including hypothalamus and brainstem ${ }^{[28]}$, suggesting that PP may also have direct effects on brain function. Pancreatic polypeptide, Neuropeptide Y (endogenous agonist, non subtype selective), Peptide YY and GR-231,118 (mixed NPY 1 antagonist / NPY 4 agonist) are the reported agonists for this receptor, whereas UR-AK49 is the antagonist for this receptor. The protein sequence of this receptor is deposited in UNIPROT database with the accession number P50391 and it is composed of 375 residues.

\subsection{The Neuropeptide Y5 Receptor}

The neuropeptide Y5 receptor was also at first identified by molecular cloning ${ }^{[29]}$. The NPY5 receptor is pharmacologically distinguished by its high affinity for both N-terminally truncated analogues of NPY and [Pro34] peptide YY. In addition, the NPY5 receptor has high affinity for human pancreatic polypeptide, but much lower affinity for rat pancreatic polypeptide. NPY5 receptor mRNA is discretely localized in rat and human brain, primarily in piriform cortex, olfactory tubercle and hypothalamus ${ }^{[30]}$. NPY5 receptor binding sites have also been detected in these regions, although some groups fail to detect NPY5 receptor binding in hypothalamus ${ }^{[31]}$. When the Y5 receptor was cloned, comparison of the feeding effects of a wider range of agonists suggested that the Y5 rather than the Y1 receptor might be a better candidate ${ }^{[32]}$. Neuropeptide $\mathrm{Y}$ (endogenous agonist, non subtype selective), BWX-46 (selective NPY5 agonist) and Peptide YY are the reported agonists for this receptor. CGP-71683, FMS586, L-152,804, Lu AA-33810, MK-0557 and NTNCB are the antagonists for $\mathrm{Y} 5$ and it is composed of 445 residues. The amino acid sequence is deposited in UNIPROT with the accession number Q15761.

\section{Sequence Analysis of Human Functional Neuropeptide Y Receptors}

Sequence analysis between these NRY receptors Y1, Y2, Y4 and Y5 were done using ClustalW and the relationship between these receptors were analyzed sequentially. Phylogram was generated to analyze the phylogenetic relationship between these receptors. Our results found that $\mathrm{Y} 1$ and $\mathrm{Y} 4$ receptors shared more identity than others. It was identified that Y1 and Y2 shared an identity of $25 \%$, whereas $\mathrm{Y} 1$ and $\mathrm{Y} 4$ shared 
sp | P25929| NPY1R sp | P50391| NPY 4R sp| P49146|NPY2R sp | Q15761|NPY5R

sp|P25929|NPY1R sp | P50391 | NPY 4R sp | P49146|NPY2R sp|Q15761|NPY5R

Sp|P25929|NPY1R sp | P50391 | NPY4R sp|P49146|NPY2R sp|Q15761|NPY5R

sp | P25929| NPY1R sp | P50391| NPY 4R sp| P49146|NPY2R sp|Q15761|NPY5R

sp|P25929|NPY1R sp| P50391|NPY4R sp| P49146| NPY2R sp|Q15761|NPY5R

sp|P25929|NPY1R sp | P50391|NPY4R sp| P49146| NPY2R sp|Q15761|NPY5R

sp| P25929|NPY1R sp | P50391 | NPY 4R SP|P49146|NPY2R sp|Q15761|NPY5R

SP|P25929|NPY1R SP | P50391 | NPY 4R sp|P49146|NPY2R sp|Q15761|NPY5R

SP|P25929|NPY1R sp | P50391 | NPY 4R SP| P49146|NPY2R sp | Q15761|NPY5R

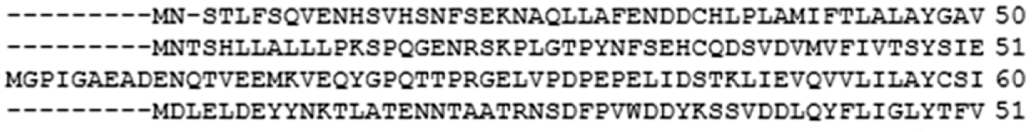

I ILGVSGNLALI I I ILRQREMRNVTNILIVNLSFSDLLVAIMCL PFTFVYTLMDHWVFGE 110 TVVGVLGNLCLMCVTVRORERANVTNLLIANLAFSDFLMCLICQPLTAVYTIMDYWIFGE 111 ILIGVIGNSLVIHVVIRFRSMRTVTNFFIANLAVADLLVNTLCIPFTLTYTLMGEWRMGP 120 SLLGFMGNLIILMALMRRRNQRTTVNFLIGNLAFSDILVVLFCSPFTITSVLIDQWMFGR 111

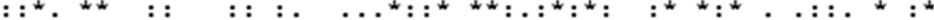

AMCRLNPFVQCVSITVSIFSIVLIAVERHOLI INPRGWRPNNRHAYVGIAVIWVLAVASS 170 TLCRMSAFIQCMSVTVS ILSLVLVALERHOL I INPTGWRPSISOAYLGIVLIWVIACVIS 171 VLCHLVPYAOGLAVQVSTITLTVIAIDRHRCIVYHLESKISRRISFLI IGLAWGISALLA 180 VMCH IMPFLQCVSVLVSTLILISIAIVRYHMIRHPISNNLTANHGYFLIATVWTLGFAIC 171

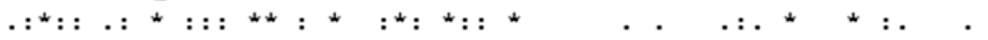

IPFIIYQVMTDEPFON--VTIDAYRDKYYCFDOFPSDS---HRLSYTTLLIVLOYFGPLC 225 LPFLANSILENVFHRNHSRALEFLADRVVCTESWPLAH---HRTIYTTFLLLFQYCLPLG 228 SPLAIFREYS--------LIEI I PDFEIVACTERWPGEERSIYGTVYSLSSLIILYVLPLG 233 SPLPVFHSLVELQET---FGSALISSRYLCVESWPSDS---YRIAFTISLILVQYILPLV 225

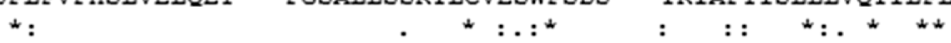

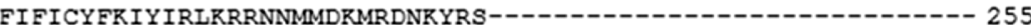

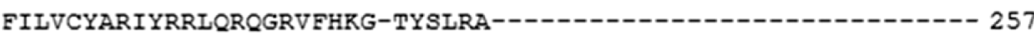

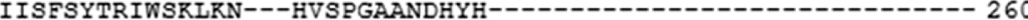
CLTVSHTSVCRSISCGLSNRENRLEENEMINLTLHPSRRSGPQVRLSGSHKWSYSFIRKH 285 : $\ldots:$ : : :

RRRYSKRTACVLPAPERPSQENHSRILPENFGSVRSQLSSSSKFIPGVPTCFEIRPEENS 345

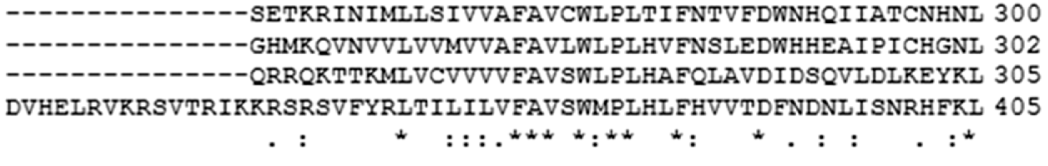

LFLLCHLTAMISTCVNPIFYGFLNRNFORDLQFFFNFCDFRSRDDDYETIAMSTMH-TDV 359 IFLVCHLLAMASTCVNPFIYGFLNTNFRKEIRALVLTCQQSAPLEESEHLPLSTVH-TEV 361 IFTVFHI IAMCSTFANPLLYGWMNSNYRRAFLSAFRCEQRLDAIHSEVSVTFRARRNLEV 365 VYCICHLIGMMSCCLNPILYGFLNNGIRADLVSLIHCLHM---------------------- 445 $:::^{\star}:{ }^{\star}{ }^{\star \star}::^{\star \star}::^{\star} \ldots:$ : . .

SRTSLRQASPVAFRRINNNDDNERI 384 SRGSLRISG-----------RSNPI 375 RRNSGPNDS----------FTEATNV 381

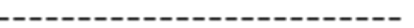

Fig. 2. Sequence alignment between $\mathrm{Y} 1, \mathrm{Y} 2, \mathrm{Y} 4$ and $\mathrm{Y} 5$ receptors.

the sequence identity of $41 \%$. Similarly, Y1 and Y5 shared an identity of $25 \%$. Moreover Y2 shared an identity of $28 \%$ with Y4 and $23 \%$ with Y5. In addition Y4 shared a sequence identity of $24 \%$ with $Y 5$. Overall, our sequence analysis found that $\mathrm{Y} 1$ and $\mathrm{Y} 4$ receptor are found to be close. They share $41 \%$ identity and a sim- ilarity of $56 \%$. Phylogram results confirmed that both $\mathrm{Y} 1$ and $\mathrm{Y} 4$ are closer than that of other functional human NPY receptors. The alignment obtained between these receptors is shown in Fig. 2 and the phylogram developed between these receptors with their distances is shown in Fig. 3. 


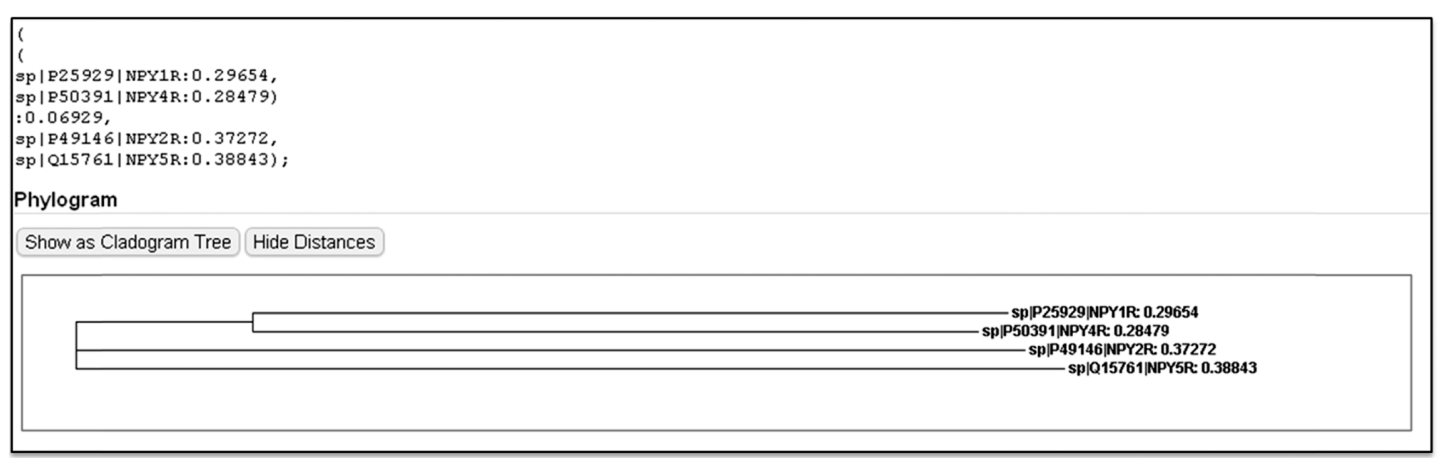

Fig. 3. Phylogenetic relationship between Y1, Y2, Y4 and Y5 receptors.

\section{Conclusion}

In this review, human functional neuropeptide $\mathrm{Y}$ receptors were reviewed. The sequence accession numbers of each receptor in the UNIPROT database were mentioned for complete information about each receptor. The natural ligands (agonists) for each receptor were reported and moreover reported antagonists of each receptor were reported in this review. Sequence analyses were done for each receptor to analyze the relationships between them. Phylogram was developed to generate the phylogenetic relationship between these receptors.

\section{Acknowledgements}

This research was supported by Basic Science Research Program through the National Research Foundation of Korea (NRF) funded by the Ministry of Education, Science and Technology (2012001465).

\section{References}

[1] K. Tatemoto, M. Carlquist and V. Mut, "Neuropeptide $\mathrm{Y}-\mathrm{a}$ novel brain peptide with structural similarities to peptide YY and pancreatic polypeptide", Nature., Vol. 296, pp. 659-660, 1982.

[2] K. Tatemoto and V. Mutt, "Isolation of two novel candidate hormones using a chemical method finding naturally occuring polypeptides", Nature., Vol. 285, pp. 417-418, 1980.

[3] Y. S. Allen, T. E. Adrian, J. M. Allen, K. Tatemoto, T. J. Crow, S. R. Bloom and J. M. Polak, "Neuropeptide Y distribution in the rat brain", Science., Vol. 221, pp. 877-8799, 1983.
[4] F. L. Bai, M. Yamano, T. Shiotani, P. C. Emson, A. D. Smith, J. F. Powell and M. Tohyama, "An arcuato-paraventricular and -dorsomedial hypothalamic neuropeptide Y-containing system which lacks noradrenaline in the rat", Brain. Res., Vol. 331, pp. 172-175, 1985.

[5] T. J. Clark, P. S. Kalra, W. R. Crowley and S. P. Karla, "Neuropeptide $\mathrm{Y}$ and human pancreatic polypeptide stimulate feeding behavior in rats", Endocrinology., Vol. 115, pp. 427-429, 1984.

[6] J. L. Miner, M. A. Della-Fera, J. A. Paterson and C. A. Baile, "Lateral cerebroventricular injection of neuropeptide Y stimulates feeding in sheep", Am. J. Physiol., Vol. 257, pp. R383-R387, 1989.

[7] R. F. Parrott, R. P. Heavens and B. A. Baldwin, "Stimulation of feeding in the satiated pig by intracerebroventricular injection of neuropeptide Y", Physiol. Behav., Vol. 36, pp. 523-525, 1986.

[8] N. Sakatani, A. Inui, T. Inoue, M. Oya, H. Morioka and S. Baba S, "The role of cholecystokinin octapeptide in the central control of food intake in the dog", Peptides. Vol. 8, pp. 651-656, 1987.

[9] B. G. Stanley, W. Magdalin, A. Seriafi, M. N. Nguyen, S. F. Leibowitz, "Evidence for neuropeptide $\mathrm{Y}$ mediation of eating produced by food deprivation and for a variant of the Y1 receptor mediating this peptide's effect", Peptides., Vol. 13, pp. 581-587, 1992.

[10] S. Herness and F. L. Zhao, "The neuropeptides CCK and NPY and the changing view of cell-to-cell communication in the taste bud", Physiol. Behav., Vol. 97, pp. 581-591, 2009.

[11] C. Wahlestedt, N. Yanaihara and R. Haakanson, "Evidence for different pre and post-junctional receptors for neuropeptide Y and related peptides", Regul. Pept., Vol. 13, pp. 307-318, 1986.

[12] A. G. Blomqvist and H. Herzog, "Y-receptor sub- 
types-how many more?", Trends in Neuroscience., Vol. 20, pp. 294-298, 1997.

[13] C. Acuna-Goycolea, N. Tamamaki, Y. Yanagawa, K. Obata and A. N. van den Pol, "Mechanisms of neuropeptide Y, peptide YY, and pancreatic polypeptide inhibition of identified green fluorescent proteinexpressing GABA neurons in the hypothalamic neuroendocrine arcuate nucleus", J. Neurosci., Vol. 25, pp. 7406-7419, 2005.

[14] S. Misra, S. Mahavadi, R. John and K. S. Murthy, "Differential expression of $\mathrm{Y}$ receptors and signaling pathways in intestinal circular and longitudinal smooth muscle", Regulatory Peptides., Vol. 125, pp. 163-172, 2005.

[15] M. M. Berglund, P. A. Hipskind and D. R. Gehlert, "Recent developments in our understanding of the physiological role of PP-fold peptide receptor subtypes", Exp. Biol. Med., Vol. 228, pp. 217-244, 2003.

[16] M. C. Michel, S. A. Beck, H. Cox, H. N. Doods, H. Herzog, D. Larhammar, R. Quirion, T. Schwartz and T. Westfall, "XVI. International Union of Pharmacology recommendations for the nomenclature of neuropeptide Y, peptide YY and pancreatic polypeptide receptors", Pharmacol. Rev., Vol. 50, pp. 143-150, 1998.

[17] I. A. Zimanyi, Z. Fathi amd G. S. Poindexter, "Central Control of Feeding Behavior by Neuropeptide Y", Curr. Pharm. Des., Vol. 4, pp. 349-366, 1998.

[18] D. Larhammar, A. G. Blomqvist, F. Yee, E. Jazin, $\mathrm{H}$. Yoo and C. Wahlested, "Cloning and functional expression of a human neuropeptide Y/peptide YY receptor of the Y1 type", J. Biol. Chem., Vol. 267, pp. 10935-10938, 1992.

[19] S. F. Leibowitz and J. T. Alexander, "Analysis of neuropeptide Y-induced feeding: dissociation of $\mathrm{Y} 1$ and Y2 receptor effects on natural meal patterns", Peptides., Vol. 12, pp. 1251-1260, 1993.

[20] P. Walker, M. Munoz, R. Martinez and M. C. Peitsch, "Acidic residues in extracellular loops of the human Y1 neuropeptide Y receptor are essential for ligand binding", J. Biol. Chem., Vol. 269, pp. 2863-2869, 1994.

[21] C. Wahlestedt, L. Grundemar, R. Hakanson, M. Heilig, G.H. Shen, Z. Zukowska-Grojec and D. Reis, "Neuropeptide Y receptor subtypes, Y1 and Y2”, Ann. N. Y. Acad. Sci., Vol. 611, pp. 7-26, 1990.

[22] Y. Dumont, A. Fournier, S. Stpierre, T.W. Schwartz and R. Quirion, "Differential distribution of neuropeptide $Y_{1}$ and $Y_{2}$ receptors in the rat brain", Eur.
J. Pharmacol., Vol. 191, pp. 501-503, 1990.

[23] Y. Dumont, A. Fournier, S. Stpierre and R. Quirion, "Comparative characterization and autoradiographic distribution of neuropeptide Y receptor subtypes in the rat brain", J. Neurosci., Vol. 13, pp. 73-86, 1993.

[24] D. A. Ammar, D. M. Eadie, D. J. Wong, Y. Y. Ma, L. F. Kolakowski, T. L. Yang-Feng and D. A. Thompson, "Characterization of the human type 2 neuropeptide Y receptor gene (NPY2R) and localization to the chromosome $4 \mathrm{q}$ region containing the type 1 neuropeptide Y receptor gene", Genomics., Vol. 38, pp. 392-398, 1995.

[25] C. Gerald, M. W. Walker, P. J. J. Vaysse, C. He, T. A. Branchek and R. L. Weinshank, "Expression cloning and pharmacological characterization of a human hippocampal neuropeptide Y/peptide YY Y2 receptor subtype", J. Biol. Chem., Vol. 270, pp. 26758-26761, 1995.

[26] P. M. Rose, P. Fernandes, J. S. Lynch, S. T. Frazier, S. M. Fisher, K. Kodukula, B. Kienzle, and R. Seethala, "Cloning and functional expression of a cDNA encoding a human type 2 neuropeptide Y receptor", J. Biol. Chem., Vol. 270, pp. 2266122664, 1995.

[27] I. Lundell, A. G. Blomqvist, M. M. Berglund, D. A. Schober, D. Johnson, M. A. Statnick, R. A. Gadski, D. R. Gehlert, and D. Larhammar, "Cloning of a human receptor of the NPY receptor family with high affinity for pancreatic polypeptide and peptide YY”, J. Biol. Chem., Vol. 270, pp. 29123-29128, 1995.

[28] M. M. Berglund, P. A. Hipskind and D. R. Gehlert, "Recent developments in our understanding of the physiological role of PP-fold peptide receptor subtypes”, Exp. Biol. Med. (Maywood)., Vol. 228, pp. 217-244, 2003.

[29] C. Gerald, M. W. Walker, L. Criscione, E. L. Gustafson, C. Batzl-Hartmann, K. E. Smith, P. Vaysse, M. M. Durkin, T. M. Laz, D. L. Linemeyer, A. O. Schaffhauser, S. Whitebread, K. G. Hofbauer, R. I. Taber, T. A. Branchek and R. L. Weinshank, "A receptor subtype involved in neuropeptide-Yinduced food intake", Nature., Vol. 382, pp. 168171, 1996.

[30] K. A. Nichol, A. Morey, M. H. Couzens, J. Shine, H. Herzog and A. M. Cunningham, "Conservation of expression of neuropeptide Y5 receptor between human and rat hypothalamus and limbic regions suggests an integral role in central neuroendocrine control", J. Neurosci., Vol. 19, pp. 10295-10304, 1999. 
[31] Y. Dumont, A. Fournier and R. Quirion, "Expression and characterization of the neuropeptide Y Y5 receptor subtype in the rat brain", J. Neurosci., Vol. 18, pp. 5565-5574, 1998.

[32] A. C. Haynes, J. R. S. Arch, S. Wilson, S. McClue and R. E. Buckingham, "Characterisation of the neuropeptide $\mathrm{Y}$ receptor that mediates feeding in the rat, role of the Y5 receptor", Regul. Pept., Vol. 75-76, pp. 355-361, 1998. 